\title{
Een skills-based \\ arbeidsmarkt in de \\ Metropoolregio Amsterdam
}

\section{Op de arbeidsmarkt wil het nog weleens voorkomen dat vraag en aanbod door toedoen van allerlei ontwikkelingen niet goed op elkaar aansluiten. Het drie jaar geleden gestarte House of Skills beoogt deze mismatch te corrigeren met behulp van een nieuwe benadering die is gebaseerd op zogeheten 'skills'.}

D00R Joost van Genabeek, Elke van der Heijden en Alex Straathof

$\mathrm{H}$ et is van algemeen belang dat vraag en aanbod van arbeid en opleidingen goed op elkaar aansluiten. Daarvan is momenteel steeds minder sprake. Terwijl in sommige sectoren functies verdwijnen door marktontwikkelingen, voortschrijdende automatisering en digitalisering, ontstaan in andere sectoren nijpende arbeidstekorten. Tegelijkertijd is het voor veel mensen lastig om de overstap te maken naar een baan in een groeisector, omdat de arbeidsmarkt georganiseerd is in een rigide systeem van sectorale functie- en opleidingseisen, dat een grote nadruk legt op formele scholing binnen de sectoren en branches. Een groeiende maatschappelijke ongelijkheid is het gevolg. Lager opgeleide werkenden maken over het algemeen weinig gebruik van scholingsmogelijkheden, verrichten vaak ongezond en zwaar werk, zijn bovengemiddeld afhankelijk van tijdelijke of flexibele contracten en lopen een relatief groot risico om (periodiek) werkloos te geraken. ${ }^{1}$ Voor het verwezenlijken van zinvolle en duurzame loopbanen is het nodig dat men op de hoogte blijft van actuele en toekomstige mogelijkheden van scholing en werk. Het is daarbij niet raadzaam om volledig af te gaan op diploma's en werkervaring, omdat deze door de snelle veranderingen al snel verouderde informatie opleveren. Wat precies nodig is om ontwikkelingen op de arbeidsmarkt bij te benen laat zich veel beter bepalen aan de hand van zogeheten 'skills'.

$\mathrm{Nu}$ missen we helaas nog veel informatie over skills. Het begint er al mee dat er vooralsnog enige onduidelijkheid bestaat over wat skills zijn. Zo wil men werkzoekenden in het duister over de vraag welke beroepen zij zouden kunnen uitoefenen op basis van hun persoonlijke verzameling aan skills. Werkgevers weten op hun beurt niet welke skills zij moeten vragen bij het uitzetten van een vacature of als zij werkzaamheden anders willen inrichten. En docenten verkeren in onzekerheid over hoe zij cursisten kunnen scholen in skills.

\section{Een onafhankelijke speler, die op basis van concrete vragen uit de arbeidsmarkt uitzoekt hoe het matchingsproces beter kan werken}

het Engelse begrip 'skills' nog wel eens naar het Nederlands vertalen met het woord 'vaardigheden'. Maar in de praktijk vallen ook competenties, kennis en eigenschappen onder het begrip 'skills'. Welke skills nodig zijn om een bepaald beroep uit te oefenen en hoe opleidingen kunnen worden vormgegeven om bepaalde skills op te doen? Ook hierover is nog veel te weinig bekend. Dientengevolge tasten nog te veel
De mismatches op de arbeidsmarkt en belemmeringen om deze aan te pakken, worden ook internationaal herkend. Onder de noemer 'Een gedeelde visie voor talent' bepleit het Wold Economic Forum (WEF) daarom een nieuw skillsecosysteem dat helpt om aanwezige skills te beschrijven, de vraag naar nieuwe skills te identificeren en individuen in staat te stellen om de juiste skills te ontwikkelen. ${ }^{2}$ Dit systeem zou 


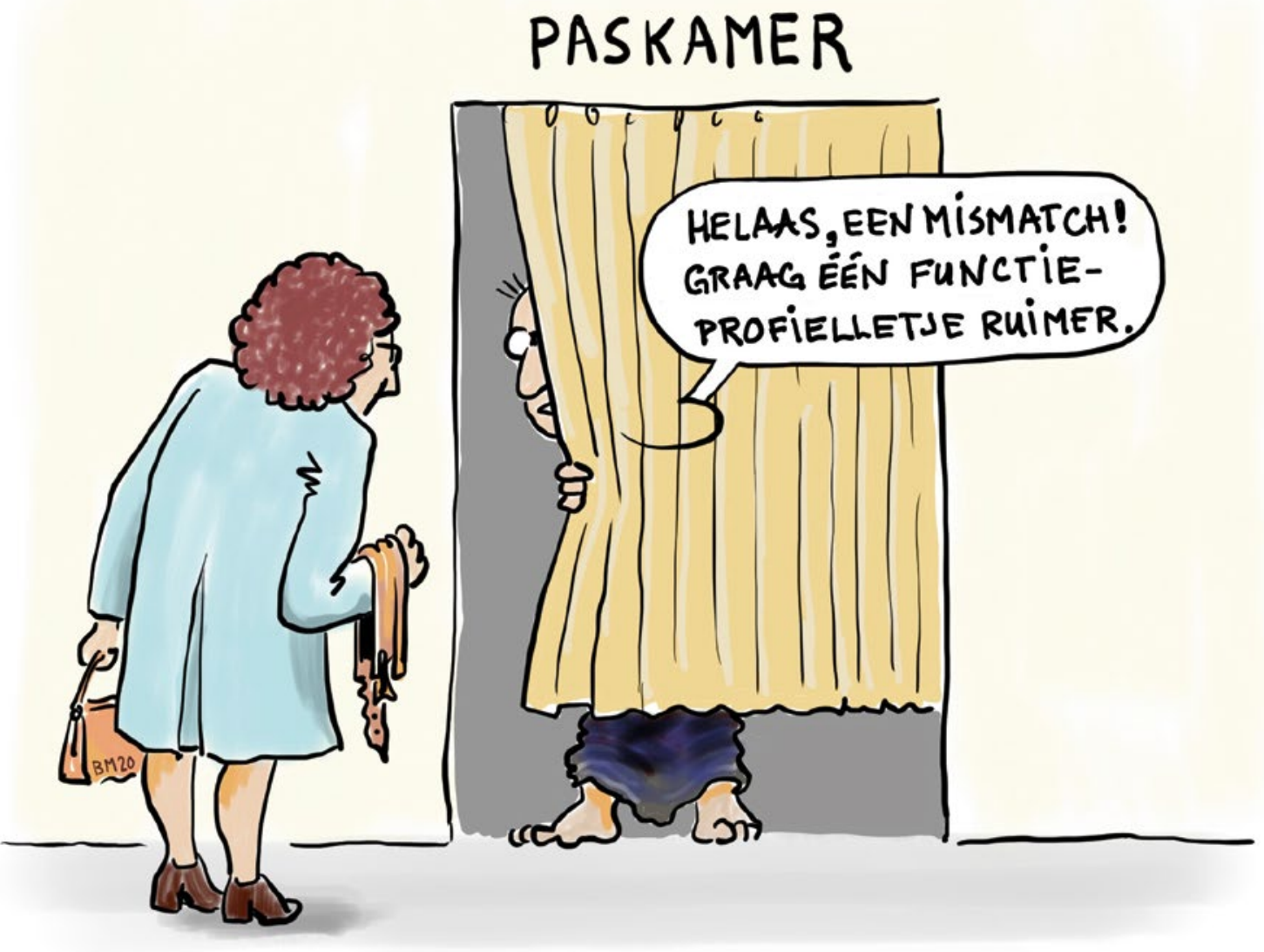

\section{HOUSE OF SKILLS - VOOR ELK WAT WILS}

regionaal, nationaal en zelfs internationaal een gemeenschappelijke wisseleenheid van skills ('munteenheid' in de terminologie van het WEF) moeten bieden voor alle individuen en organisaties op de arbeidsmarkt, waarmee intersectorale mobiliteit op de arbeidsmarkt vergemakkelijkt wordt.

\section{Complexe systeeminnovatie}

House of Skills heeft de maatschappelijke opdracht om zo'n skills-ecosysteem tot stand te brengen voor de Metropoolregio Amsterdam. Het gaat hier om een complexe systeeminnovatie. De ontwikkeling van een skills-ecosysteem vergt namelijk veranderingen op verschillende niveaus, domeinen en institutionele settingen tegelijk: binnen en tussen bedrijven en overheden, en in het onderwijs. In die context moeten keuzes worden gemaakt die afwijken van de gangbare praktijken, structuren en relaties. Om deze complexe systeeminnovatie mogelijk te maken is er in 2017 een publiek-private samenwerking tot stand gebracht van gemeenten, het UWV, beroepsonderwijs, ${ }^{3}$ intermediairs, ${ }^{4}$ vakcentrales FNV en CNV, werkgeversorganisaties ${ }^{5}$ en kennispartners. ${ }^{6}$

Het doel van House of Skills is om mismatches op de regionale arbeidsmarkt te verminderen door te investeren in levenslange ontwikkeling en vergroting van de duurzame inzetbaarheid op de arbeidsmarkt van met name lager- en middelbaar opgeleiden. Hiertoe ontwikkelt House of Skills (digitale) producten en diensten die aansluiten op het reguliere aanbod van de publieke en de private sector. Tegelijkertijd stimuleert House of Skills ketensamenwerking tussen onderwijs, bedrijfsleven, gemeenten en het UWV, waarin deze producten en diensten worden toegepast. House of Skills is hierin een onafhankelijke speler, die in de praktijk op basis van concrete vragen uit de arbeidsmarkt uitzoekt hoe het matchingsproces beter kan werken. House of Skills vormt bovendien een innovatie-community voor kennisdeling, netwerken en lobby. Deze kerntaken van House of Skills worden ondersteund door onderzoek en ontwikkeling. Om vorm te geven aan de gemeenschappelijke wisseleenheid ('munteenheid') van skills, heeft House of Skills ervoor gekozen om de producten en diensten te baseren op gevalideerde skills-taxonomieën. Een skills-taxonomie biedt een systematische rangschikking van skills die nodig zijn voor het beoefenen van beroepen of functies, of voor het vaststellen van opleidingsbehoeften. Skills-taxonomieën zijn er in alle soorten en maten. Sommige richten zich op bepaalde sectoren, branches of bedrijven, andere bestrijken de gehele arbeidsmarkt. Bij sommige taxonomieën zijn de methoden en de bronmaterialen van de rangschikking openbaar toegankelijk (open source), bij andere is dat niet of slechts gedeeltelijk het geval. Voor House of Skills zijn met name de open source skills-taxonomieën relevant die de gehele arbeidsmarkt bestrijken. Voorbeelden zijn O*NET uit de VS (www.onetonline.org), ESCO voor de 


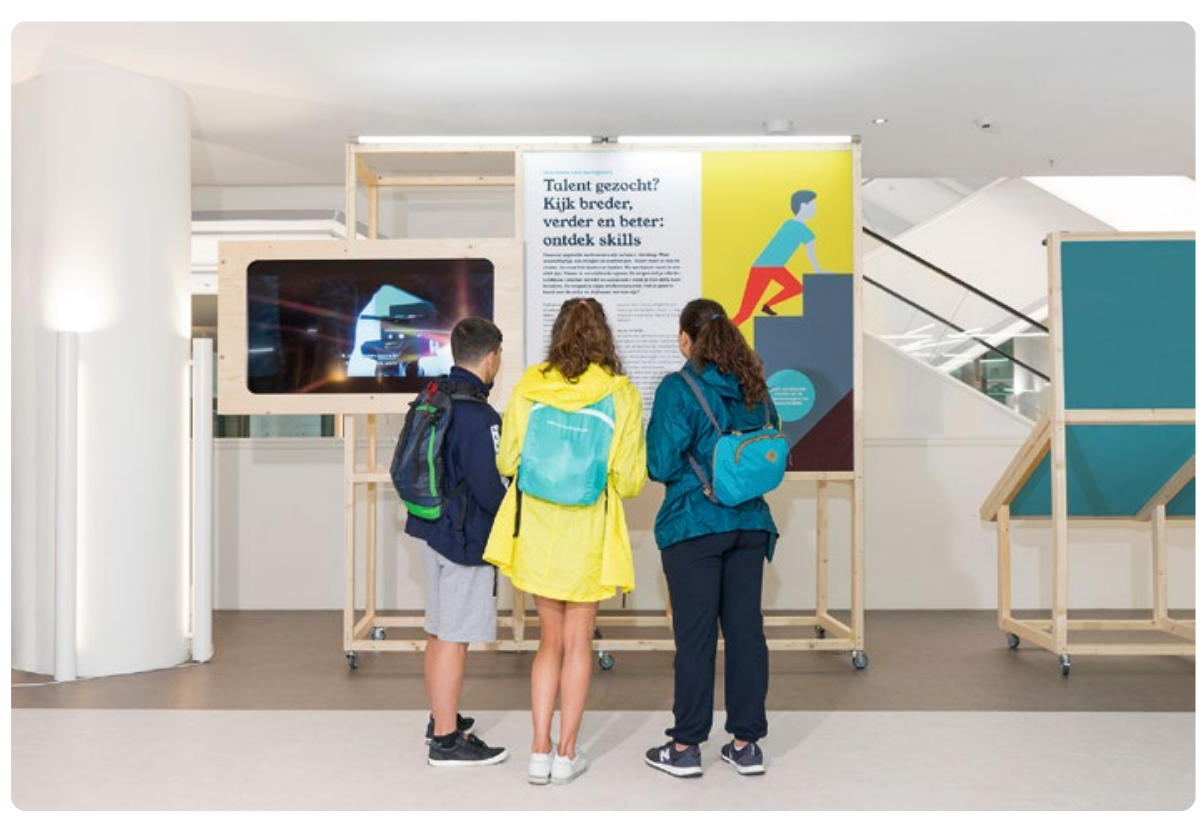

Europese Unie (https://ec.europa.eu/ esco/) en het Vlaamse Competent (www.vdab.be/competent).

House of Skills heeft de afgelopen jaren een breed scala aan (digitale) producten en diensten ontwikkeld en deze uitgeprobeerd. House of Skills richt zich voornamelijk op het lager en middensegment van de arbeidsmarkt en zet de producten en diensten actief in bij regionale pilots gericht op specifieke doelgroepen, zoals voor vrachtafhandelaars op Schiphol, functies in de bouw en de techniek, of apothekersassistenten. Wegens het grote tekort aan apothekersassistenten in de MRA is bijvoorbeeld een zij-instroomtraject ontwikkeld met een groot aantal partners (onder andere TNO, Stichting Brancheorganisatie Apothekersassistenten, FBA, ROC van Amsterdam, Bureau Nieuwzorg, WSP en UWV). De eerste pilot startte in het voorjaar van 2019 met 25 kandidaten. In het huis-aan-huisblad van de gemeente Amsterdam is dit traject onder de aandacht gebracht. Dit heeft 700 reacties van geïnteresseerden en apothekers opgeleverd. Uiteindelijk hebben 400 kandidaten deelgenomen aan een loopbaantraject met diensten van House of Skills, waarvan 25 gestart zijn in de tweede ronde. In totaal zijn 50 apothekersassistenten aan de slag in dit traject, die voorheen een WWB- of WW-uitkering ontvingen of als niet-uitkeringsgerechtigde werkzoekenden stonden ingeschreven bij de gemeenten. De overige kandidaten met wie gesprekken zijn gevoerd, zijn deels doorgeleid naar andere zorgvacatures. In november 2019 startte het derde traject en de volgende rondes zijn al weer voorzien.

De producten zijn via House of Skills ook landelijk en voor andere doelgroepen op de arbeidsmarkt beschikbaar. In het navolgende lichten we de producten en diensten nader toe.

\section{De Werkvloer}

Op 18 juni 2019 is De Werkvloer van House of Skills geopend op de eerste etage van de centrale Openbare Bibliotheek Amsterdam. De Werkvloer is een locatie waar iedereen zich kan toekomst, en welke skills daarbij worden gevraagd. De Werkvloer heeft een inloop- en informatiefunctie. Bezoekers kunnen er een loopbaangesprek voeren met een loopbaancoach, via workshops kennismaken met beroepen waarbinnen een groot personeelstekort voorkomt en zich informeren over actuele ontwikkelingen op de arbeidsmarkt in de Metropoolregio Amsterdam, aan de hand van informatiepanelen, animaties en films. Speciale aandacht is er voor de kansen die de energietransitie en de zorg bieden. De Werkvloer is ook dé plek waar de partners van House of Skills elkaar ontmoeten in werkateliers om gezamenlijk plannen te maken. MijnHouseofSkills ${ }^{7}$ is een digitaal platform dat vrij toegankelijk is voor werkenden, werkzoekenden en bedrijven. Het heeft als doel om inzichtelijk te maken welke opleidingen, beroepen en vacatures passen bij werkenden en oriënteren op werk van nu en in de werkzoekenden. Het basisprincipe is dat opleidingen en banen weergegeven kunnen worden als een reeks skills die mogelijk veranderen door de tijd heen. Aan de hand van hun vooropleiding en werkverleden krijgen gebruikers aangereikt welke beroepen en opleidingen aansluiten bij hun skills. Per beroep biedt MijnHouseofSkills een tekstuele beschrijving, een video en een uiteenzetting van de skills. Gebruikers kunnen tevens zoeken in een overzicht van passende openstaande (en recent gesloten) vacatures die zich bevinden binnen de door henzelf aangegeven reisafstand. MijnHouseofSkills is in juni 2020 gelanceerd.

\section{De Paskamer ${ }^{8}$}

De Paskamer heeft tot doel om zowel werkenden en werkzoekenden als bedrijven bewust te maken van de skills die nodig zijn voor het uitoefenen van bepaald werk. De Paskamer levert werkenden en werkzoekenden informatie over hun skills en geeft hun inzicht in de beroepen en functies die daarbij passen. Bedrijven verkrijgen met De Paskamer inzicht in de skills die nodig zijn voor functies waar zij personeel voor zoeken. Dit inzicht kan de effectiviteit van de werving vergroten, omdat het bedrijven in staat stelt nauwgezet aan te geven wat er van kandidaten verwacht wordt. Tot slot vergroot De Paskamer de mogelijkheden voor werkenden/werkzoekenden en bedrijven om elkaar te vinden door aangeboden en gevraagde skills op de arbeidsmarkt bij elkaar te brengen. Het focussen op skills in plaats van diploma's of werkervaring, makkt ook minder voor de hand liggende combinaties inzichtelijk tussen taakeisen van banen of functies en de geschiktheid van kandidaten. De Paskamer biedt gedetailleerde informatie voor het aanpassen van het werk aan de persoon (baanherontwerp of jobcrafting), voor het inrichten van aanvullende scholing en over mogelijkheden van intersectorale mobiliteit. Ruim 1.200 werkzoekenden hebben een account aangemaakt voor De Paskamer, van wie circa 800 een volledig skillsprofiel hebben opgesteld. Daarnaast hebben 20 bedrijven en branches functieprofielen aangemaakt in De Paskamer.

Het Skillspaspoort heeft tot doel om het 'reizen' op de arbeidsmarkt te faciliteren 
voor werkenden en werkzoekenden. Cruciaal daarvoor is dat het paspoort herkend en erkend wordt door de beroepsbevolking, de werkgevers en het onderwijs. Net als een gewoon paspoort is het Skillspaspoort een persoonlijk document. Het biedt op een overzichtelijke manier inzicht in de skills op basis van verschillende niveaus van bewijsvoering: hard in de vorm van diploma's en certificaten (EVC), semi-hard via projectinformatie en urenstaten van arbeidsorganisaties, en zacht in de vorm van persoonlijke loopbaanoriëntatie en assessments (zoals De Paskamer). House of Skills ontwikkelt het Skillspaspoort in een drietal pilots: 1) voor de bagageafhandelaars op de luchthaven Schiphol, 2) voor medewerkers in de bouw en installatietechniek (samen met Bouwend Nederland en Techniek Nederland) en 3) voor studenten binnen opleidingen van de HvA, ROCvA en ROC NOVA. Uitgangspunt is dat iedere pilot kennis en leerervaringen oplevert die bijdragen aan de ontwikkeling van een sectoroverstijgend Skillspaspoort voor de Metro- gevormd hebben over hoe zij daar kunnen komen. De loopbaanbegeleiding is beschikbaar voor iedereen die wil nadenken over de eigen loopbaan en het werk dat daarbij past. Werkzoekenden kunnen zich aanmelden via bedrijven en brancheverenigingen in het netwerk van House of Skills, maar ook via het UWV, vakbonden en op eigen initiatief. Voor de pilots van House of Skills worden ook advertenties geplaatst in lokale bladen. De loopbaancoaches van House of Skills hebben inmiddels circa 1.500 werkzoekenden begeleid. De COVID-19 pandemie heeft de arbeidsmarkt plotseling voor nieuwe uitdagingen gesteld. De Metropoolregio Amsterdam wordt bovenmatig geraakt omdat de regionale economie steunt op kwetsbare sectoren als toerisme, cultuur, de evenementenindustrie en de internationale zakelijke dienstverlening. ${ }^{9}$ De grote vraag naar zorgpersoneel en de snelle toename van de werkloosheid hebben House of Skills versneld in een implementatiefase gebracht. Daarbij zijn zogeheten transferpunten opgericht:

\section{House of Skills zet zijn producten en diensten in bij regionale pilots gericht op specifieke doelgroepen}

poolregio Amsterdam. Daarbij wordt zoveel mogelijk aangesloten op de standaarden die landelijk en in Europees verband tot stand zijn gebracht.

\section{Loopbaanbegeleiding}

Binnen House of Skills zijn gecertificeerde loopbaancoaches actief die onafhankelijk en gratis gesprekken voeren met personen die op zoek zijn naar (ander) werk. De loopbaancoaches gaan op een gestructureerde wijze samen met de werkzoekenden op zoek naar antwoorden op vragen over werk en loopbaan. Werkzoekenden vullen dan De Paskamer in en doen eventueel andere tests, voeren opdrachten uit en vragen in hun omgeving om feedback. De bedoeling is dat de werkzoekenden na afloop van de loopbaanbegeleiding beter weten waar hun sterke kanten liggen, zicht hebben op de mogelijkheden van werk en opleiding en een concreet beeld samenwerkingsverbanden waarin mensen snel worden begeleid van werk naar nieuw werk. Met behulp van de eerder besproken producten en diensten verbinden de transferpunten werkzoekenden, onderwijsinstellingen en werkgevers procesmatig met elkaar. Een voorbeeld hiervan is het Transferpunt Zorg en Welzijn. Landelijke acties zoals www.extrahandenvoordezorg.nl/ zijn gericht op het vinden van personeel dat direct inzetbaar is. De behoefte aan personeel is echter groter. Het Transferpunt Zorg en Welzijn is om die reden tevens bedoeld voor mensen die gemotiveerd zijn om in de zorg te werken, maar onvoldoende daartoe zijn opgeleid. Het transferpunt brengt hun skills en motivatie in kaart en vergelijkt deze met de arbeidsbehoefte van zorginstellingen. Opleidingsinstituten vullen waar nodig ontbrekende skills aan door middel van kortdurende opleidingen. Dergelijke transferpunten worden ook opgezet voor Schiphol, de techniek, de bouw, de duurzaamheidsopgave, jongeren en mbo-studenten.

\section{Vruchten plukken}

De transferpunten zijn geen nieuwe institutie voor arbeidsbemiddeling, maar sluiten aan op bestaande processen van bijvoorbeeld het UWV, sociale diensten van gemeenten, werkgeverservicepunten en uitzendbureaus. Producten en diensten van House of Skills worden zodanig vervlochten dat bestaande instituties de vruchten kunnen plukken van de skillsbenadering. In 2021 zal House of Skills een duurzame, uitvoerende organisatie met een rechtspersoon gaan vormen, teneinde continuiiteit te bewerkstelligen in de voortgaande transitie naar een onderwijsaanbod en een arbeidsmarkt die op skills zijn gebaseerd. Bestaande instituties in de regio en de rest van Nederland worden uitgenodigd om hun processen te baseren op hetzelfde basisprincipe. Dit maakt het mogelijk om nog breder gezamenlijk te werken aan het terugdringen van mismatches op de arbeidsmarkt. Een zo breed mogelijke ketensamenwerking speelt immers het beste in op snelle veranderingen in vraag en aanbod van arbeid als gevolg van economische crises of hoogconjunctuur.

\section{Noten}

1 WRR (2020). Het betere werk. De nieuwe maatschappelijke opdracht.

2 World Economic Forum (2019). Strategies for the New Economy. Skills as the Currency of the Labour Market.

3 Het gaat om ROC van Amsterdam en ROC Nova.

4 James Loopbaanbegeleiding (gelieerd aan CNV), Manpower en Randstad.

5 AWVN en Techniekraad Noord-Holland.

6 De Hogeschool van Amsterdam, Hogeschool Windesheim, Hogeschool Saxion, Hogeschool Arnhem-Nijmegen, Universiteit van Amsterdam, SEO, VU en TNO.

7 https://www.houseofskillsregioamsterdam.nl/ instrumenten/platform-mijnhouseofskills/

8 https://www.houseofskillsregioamsterdam.nl/ instrumenten/de-paskamer/

9 Smits, T., Tieben, B. (2020). De economische impact van bet coronavirus in de MRA en Groot-Amsterdam. Gevolgen voor de economische groei en de werkgelegenheid. SEO Economisch Onderzoek. 